\title{
What Can be Done for Large and Multiple Choledochal Stones?
}

\author{
Ufuk Arslan, Haci Murat Cayci, Ali Tardu and Umut Eren Erdogdu \\ Department of General Surgery, University of Medical Sciences, Bursa Yuksek Ihtisas Training and Research Hospital, Bursa, Turkey
}

\begin{abstract}
Endoscopic retrograde cholangiopancreatography may fail to extract large and multiple choledochal stones in a single session, necessitating a repeat procedure. This paper presents the case of a 68-year female patient who underwent stone extraction following endoscopic retrograde cholangiopancreatography and a subsequent biliary stenting procedure for multiple choledochal stones. Cholelithiasis and choledocholithiasis were detected in the above patient presenting with abdominal pain and jaundice. Conventional endoscopic retrograde cholangiopancreatography techniques failed to extract the stones, and the patient subsequently underwent a sequential insertion of multiple biliary stents. The procedure was used to facilitate the downsizing and fragmentation of the stones. The duct was then cleared using the balloon/basket technique. No problem occurred within the follow-up period and the patient underwent a successful cholecystectomy four weeks after the procedure. Multiple stenting is one treatment method that can be performed in selected patients with large and multiple choledochal stones.
\end{abstract}

Key Words: Choledocholithiasis, Endoscopic retrograde cholangiopancreatography (ERCP), Biliary stenting.

How to cite this article: Arslan U, Cayci HM, Tardu A, Erdogdu UE. What Can be Done for Large and Multiple Choledochal Stones? J Coll Physicians Surg Pak 2020; 30(04):435-437. DOI: https://doi.org/10.29271/jcpsp.2020.04.435.

\section{INTRODUCTION}

Endoscopic retrograde cholangiopancreatography (ERCP) is commonly used in the diagnosis and treatment of bile stones. However, the presence of large and multiple stones, distal common bile duct (CBD) variations, the presence of periampullary diverticula and a past history of surgery of the bile duct, stomach and duodenum can all decrease the chances of successful stone retrieval. ${ }^{1}$ Full stone extraction cannot be achieved by ERCP in $10-15 \%$ of patients with complicated choledochal stones (larger than $15 \mathrm{~mm}$ and/or more than 3 ) and such patients may require repeatERCP procedures. ${ }^{2}$

Large stones ( $>2 \mathrm{~cm}$ ) often require fragmentation through extracorporeal shock wave lithotripsy (ESWL) or laser lithotripsy. ${ }^{3}$ Despite their efficacy, these methods are not available in all centres and even increases the treatment duration. Older patients with comorbidities, in particular, cannot tolerate prolonged procedures. ${ }^{4}$ Alternatively, multiple biliary stenting, with sequential ERCP procedures for the treatment of large stones, facilitates the downsizing and fragmentation of the stones and serves as a bridging treatment until the next intervention, thus facilitating the retrieval of stones in follow-up endoscopic interventions. $^{5}$

Correspondence to: Dr. Ufuk Arslan, Department of General Surgery, University of Medical Sciences, Bursa Yuksek Ihtisas Training and Research Hospital, Bursa, Turkey E-mail:drufuk33@hotmail.com

Received: August 05, 2019; Revised: October 11, 2019;

Accepted: October 11, 2019

DOI: https://doi.org/10.29271/jcpsp.2020.04.435
This report presents the case of a patient with multiple large choledochal stones who was treated by multiple biliary stenting with planned and sequential ERCP.

\section{CASE REPORT}

A 68-year female patient presented to our outpatient clinic with complaints of abdominal pain and jaundice lasting approximately two weeks. Incidents of interest from her medical history were history of appendectomy, hypertension and type 2 diabetes mellitus. Upon physical examination, the patient was found to have scleral icterus, while the abdomen was normal. Vital signs were stable and arterial blood pressure was $130 / 85 \mathrm{mmHg}$, fasting blood glucose was $105 \mathrm{mg} / \mathrm{dl}$, and body temperature was $37^{\circ} \mathrm{C}$. Laboratory test results were as follows: white blood cells: 9,200/ $\mathrm{mm}^{3}$, hemoglobin: $11.2 \mathrm{~g} / \mathrm{dl}$, neutrophils: 5,600/ $\mathrm{mm}^{3}$. Biochemistry values were: aspartate aminotransferase: $35 \mathrm{U} / \mathrm{L}$; alanine aminotransferase: $44 \mathrm{U} / \mathrm{L}$; alkaline phosphatase (ALP): $345 \mathrm{U} / \mathrm{L} ;$ gamma glutamyltransferase (GGT): $285 \mathrm{U} / \mathrm{L}$; total bilirubin: $4.4 \mathrm{mg} / \mathrm{dl}$; direct bilirubin: $4.1 \mathrm{mg} / \mathrm{dl}$; C-reactive protein: $5 \mathrm{mg} / \mathrm{L}$; and erythrocytesedimentation rate: $12 \mathrm{~mm} / \mathrm{hr}$. An abdominal ultrasound revealed multiple stones in the gall bladder, the largest measuring $2 \mathrm{~cm}$. Magnetic resonance cholangiopancreatography (MRCP) showed multiple large stones (larger than 15 $\mathrm{mm}$ ) in the common bile duct, the diameter of which was $2 \mathrm{~cm}$. The intrahepatic bile ducts and pancreatic duct were of normal width (Figure 1a).

The patient underwent endoscopic cholangiography and sphincterotomy (Figure 1b). However, the stones observed on MRCP could not be retrieved using conventional methods during the first session of ERCP. We evaluated the options of endoscopic and surgical interventions in consultation with the patient, and the possible risks of these interventions. Due to the unavailability of ESWL and laser lithotripsy in our hospital, downsizing of the stones 
through the insertion of multiple stents into the common bile duct was planned. To this end, a $10 \mathrm{~F}$ plastic biliary stent was placed in the common bile duct every 15 days. The serum enzymes associated with cholestasis decreased after the first procedure and abdominal pain disappeared. By the end of six months, a total of 11 plastic biliary stents had been placed in the patient (Figure $2 a$ ). During the $12^{\text {th }}$ procedure, a shedding of small stone fragments from the papilla was observed. At this point, the stents were removed from the common bile duct (Figure $2 b$ ) and the extrahepatic bile duct was cleaned thoroughly using the balloon/basket technique. A confirmed cholangiography revealed no remaining stones in the extrahepatic bile ducts, and the patient underwent a laparoscopic cholecystectomy four weeks later. The patient reported no problem at the follow-up visit, two months after surgery.
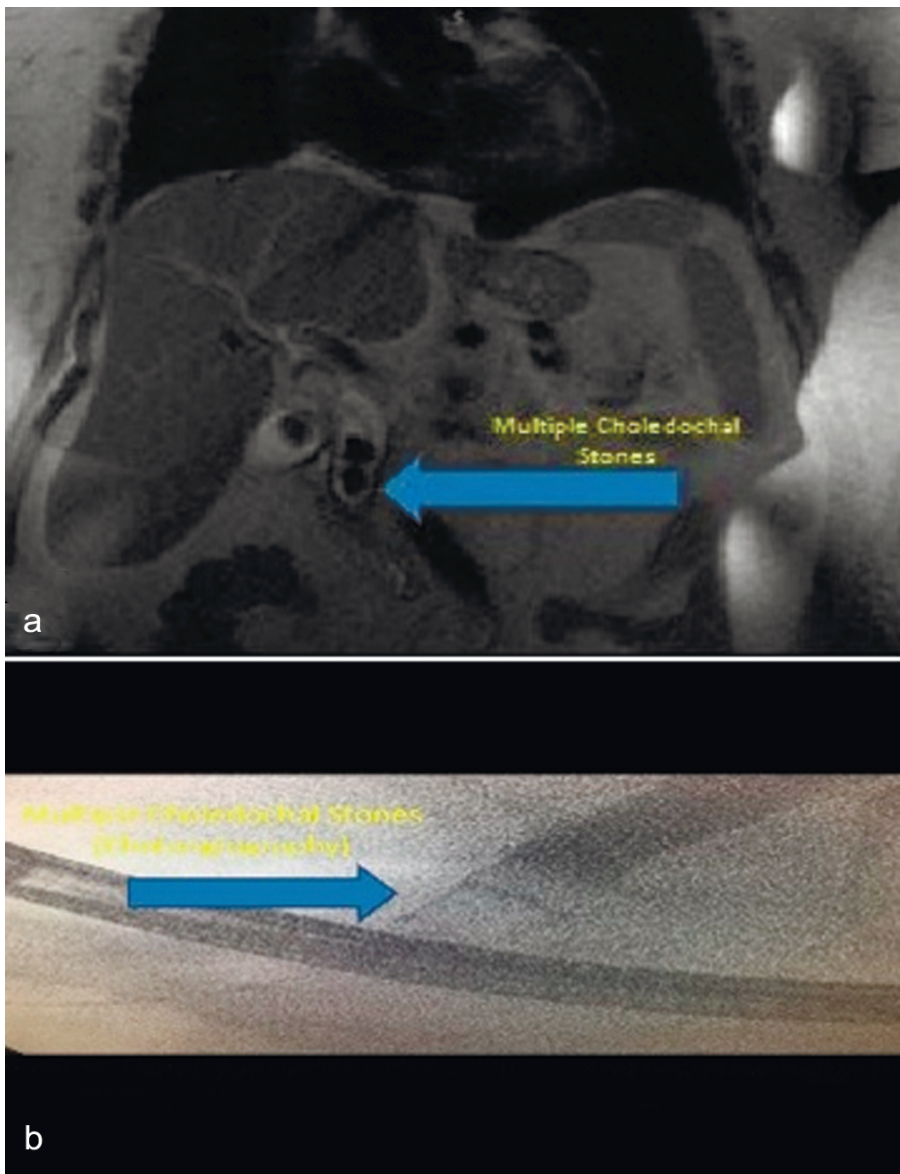

Figure 1 (a,b): Magnetic resonance cholangiopancreatography (MRCP) showing multiple large. choledochal stones.

\section{DISCUSSION}

Choledocholithiasis is one of the most common gastrointestinal diseases requiring therapeutic endoscopic procedures. Conventional ERCP techniques (sphincterotomy, balloon or basket techniques) may fail in stone extraction in $10-15 \%$ of patients with large and multiple choledochal stones. ${ }^{1,4}$ Technical difficulties, associated with stone extraction from the distal CBD, are determined by the size and number of stones; and the rate of successful stone extraction decreases with increasing stone size. ${ }^{6,7}$ Temporary plastic stents are placed to relieve biliary obstructions when the stones cannot be extracted from the CBD, and it has been demonstrated that large stones decrease in size and even disap- pear after the insertion of multiple stents. ${ }^{5}$ Endoscopic large balloon dilatation or lithotripsy is performed for non-impacted stones and multiple biliary stenting is recommended for patients whose stones cannot be removed. ${ }^{8}$

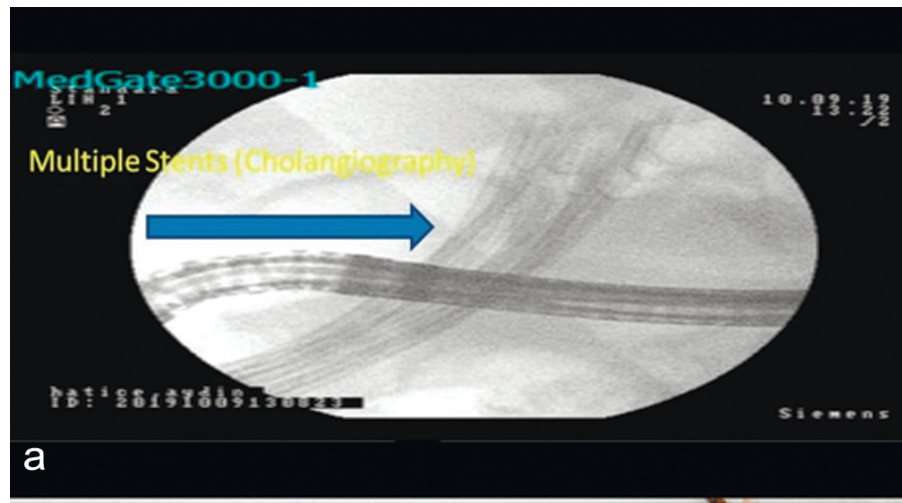

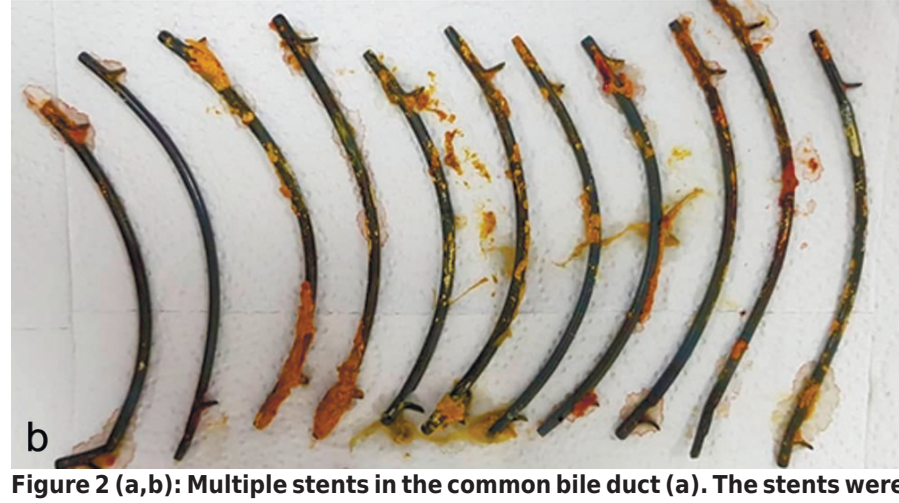
Figure $2(a, b)$ : Multiple stents in the com
removed from the common bile duct $(b)$.

While it was apparent from the MRCP and ERCP that the large stones detected during cholangiography could not be extracted in a single session, all stones were eventually eradicated after the insertion of multiple stents with sequential ERCP. Multiple biliary stenting was found to be an effective method for high-risk elderly patients with CBD stones. ${ }^{7}$

The exact mechanisms responsible for the decrease in size and number of stones following multiple stenting are unclear. It appears that multiple stenting of the extrahepatic bile duct causes friction due to respiratory movements and bowel peristalsis, which facilitates passage through the ampulla, thus providing continuity of biliary drainage. It is also possible that multiple stenting may prevent stone formation by decreasing calcium bilirubinate accumulation. ${ }^{6}$ At the same time, $10 \mathrm{~F}$ stents are associated with fewer obstructions and are in common use in our clinic. ${ }^{9}$ In the current case, while there was no biliary obstruction following multiple stenting, a definite decrease in the size of stones was observed.

Despite the known efficacy of ERCP and biliary stenting, there is a limited body of knowledge regarding multiple biliary stenting and its efficacy. ${ }^{10}$ It seems that a stone extraction technique involving temporary plastic biliary stent placement can be successfully performed in geriatric and high-risk patients, when stones in the CBD cannot be retrieved completely. This approach results in a decrease in both procedure time and in complication rate following ERCP. ${ }^{11}$ That said, repeated ERCP procedures, increased total procedure time and the potential for complications in individual procedures can be considered as disadvantages of this 
method. There is also potential for pancreatitis (5\%) and stent migration to occur following multiple plastic biliary stent placements, although neither problem developed in the present case. ${ }^{5}$

When the cost is evaluated, all the health services in our country are free of charge, the cost of surgical intervention (CBD exploration) is approximately 1,035 USD and the cost of endoscopic stent placement is 52 USD persession.

Multiple stenting with ERCP can be considered a safe, alternative method in selected patients with large, multiple choledochal stones.

\section{PATIENTS' CONSENT:}

Informed consent was obtained from the patient.

\section{CONFLICT OF INTEREST:}

Authors declared no conflict of interest.

\section{AUTHORS' CONTRIBUTION:}

$U A$ : Design of the work and ERCP.

HMC: Drafting the work and ERCP.

AT: Drafting the work and writing.

UEE: Drafting the work and writing.

\section{REFERENCES}

1. Freeman ML, Nelson DB, Sherman S, Haber GB, Herman ME, Dorsher PJ, et al. Complications of endoscopic biliary sphincterotomy. N Engl J Med 1996; 335:909-18.

2. Yasuda I. Management of the bile duct stone: Current situation in Japan. Dig Endosc 2010; 22:76-8.

3. Shaw MJ, Mackie RD, Moore JP, Dorsher PJ, Freeman ML, Meier $\mathrm{PB}$, et al. Results of a multicenter trial using a mechanical lithotripter for the treatment of large bile duct stones. Am J Gastroenterol 1993; 88:730-3.

4. Lee TH, Han JH, Kim HJ, Park SM, Park SH, Kim SJ. Is the addition of choleretic agents in multiple double-pigtail biliary stents effective for difficult common bile duct stones in elderly patients: A prospective multicenter study. Gastrointest Endosc 2011; 74:96-102.

5. Horiuchi A, Nakayama Y, Kajiyama M, Kato N, Kamijima T, Graham DY, et al. Biliary stenting in the management of large or multiple common bile duct stones. Gastrointest Endosc 2010; 71:1200-3e2.

6. Hong WD, Zhu QH, Huang QK. Endoscopic sphincterotomy plus endprostheses in the treatment of large or multiple common bile duct stones. Dig Endosc 2011; 23:240-3.

7. Akazawa Y, Ohtani M, Nosaka T, Saito Y, Takahashi K, Naito T, et al. Long-term prognosis after biliary stenting for common bile duct stones in high-risk elderly patients. J Dig Dis 2018; 19:626-34.

8. Kedia P, Paul RT. Endoscopic management of complex biliary stone disease. Gastrointest Endosc Clin N Am 2019; 29: 257-75.

9. Kadakia SC, Starnes E. Comparison of 10 French gauge stent with 11.5 French gauge stent in patients with biliary tract diseases. Gastrointest Endosc 1992; 38:454-9.

10. Bektas H, Gurbulak B, Sahin ZD, Duzkoylu Y, Colak S, Gurbulak EK, et al. Multiple plastic biliary stent placement in the management of large and multiple choledochal stones: Single center experience and review of the literature. Wideochir Inne Tech Maloinwazyjne 2017; 12:231-7.

11. Pisello F, Geraci G, Li Volsi F, Modica G, Sciume C. Permanent stenting in "unextractable" common bile duct stones in high risk patients. A prospective randomized study comparing two different stents. Langenbecks Arch Surg 2008; 393:857-63. 